\title{
Is PEEK cage better than titanium cage in anterior cervical discectomy and fusion surgery? A meta-analysis
}

\author{
Zhi-jun $\mathrm{Li}^{1 *+}$, Yao Wang ${ }^{2+}$, Gui-jun $\mathrm{Xu}^{3}$ and Peng Tian ${ }^{3}$
}

\begin{abstract}
Background: This meta-analysis was performed to identify the benefits and disadvantages of the PEEK cage and titanium cage.

Methods: We used "cervical or cervicle", "titanium", and "polyetheretherketone or PEEK" as keywords. Medline, Embase, Cochrane Central Register of Controlled Trials and other databases were searched to identify eligible studies that were published before October 2015. In addition, the Google search engine was used to manually search for relevant journals or conference proceedings. Randomized controlled trials and non-randomized controlled trials that compared the PEEK cage and titanium cage for anterior cervical surgery were included. The meta-analysis was performed with RevMan 5.1 software.

Results: Two randomized and two non-randomized clinical trials were retrieved with a total of 184 segments from 107 patients in the PEEK cage group and 211 segments from 128 patients in the titanium cage group. The quality assessment scores ranged from 16 to 18 with high heterogeneity. There were no differences in functional status according to the Odom criteria, fusion rate, final local segmental angle and loss of correction between the two groups. Although more subsidence occurred in the titanium cage group, the effects of loss of the local segmental angle or the whole cervical Cobb angle on cervical function in the long-term are still not clear.

Conclusion: The present meta-analysis indicated no significant difference in functional and radiographic performance between the PEEK and titanium cages, although more subsidence occurred in the titanium cage group. More high-quality studies are needed to confirm these results to offer more information for the choice in clinical practice.
\end{abstract}

Keywords: Titanium, Polyetheretherketone, Cage, Cervical spine, Meta-analysis

Abbreviations: ACDF, Anterior cervical discectomy and fusion; Cl, Confidence interval; MINORS, Methodological index for non-randomized studies; MD, Mean difference; NDI, Neck disability index; OR, Odds ratios;

PEEK, Polyetheretherketone; RCTs, Randomized controlled trials.

\section{Background}

Anterior cervical discectomy and fusion (ACDF), introduced by Cloward [1], has been accepted as the standard procedure for the treatment of myelopathy and radiculopathy in the cervical spine [2,3]. A tricortical iliac crest bone graft is the traditional inter-body fusion material

\footnotetext{
* Correspondence: hansontijmu@gmail.com

${ }^{\dagger}$ Equal contributors

${ }^{1}$ Department of Orthopedics, Tianjin Medical University General Hospital, No.154, Anshan Road, Tianjin 300052, People's Republic of China

Full list of author information is available at the end of the article
}

that can show perfect bony fusion and maintain the patency of the neuroforamen. However, donor site complications were reported in fusion with an iliac bone graft, such as subcutaneous hematomas, infections, and chronic wound pain [4].

To immobilize the unstable motion segment after discectomy, we have to ensure bony fusion and avoid donor site complications at the same time; some fusion devices have been developed for stand-alone use or use in combination with an anterior plate. As described by Bagby [5], cage fusion technology originated from a surgery by 
Bagby, some veterinary surgeons and the distraction compression method and was the basic principle for stand-alone intervertebral cage fusion. Although the principle was invented to solve a cervical problem, the carbon fiber fusion cage [6] and titanium cage [7] were first used for lumbar inter-body fusions, and they were then applied to treat cervical spinal degenerative lesions by Hacker [8] and Profeta [9] in 2000. Currently, the titanium cage and polyetheretherketone (PEEK) cage are the two most common cages in clinical practice. The ideal cage has to have a high fusion rate and prevent complications, such as subsidence and loss of correction.

Even though a titanium cage can provide long-term stabilization, increase lordosis, and increase foramina height compared with the iliac bone graft [10], some inferior clinical outcomes appeared in clinical practice. Loss of correction is a major complication of subsidence that may eventually affect cervical spinal function after the operation. The incidence of subsidence for the titanium cage varied as reported by Gercek who retrospectively reviewed eight patients who received ACDF with a stand-alone titanium cervical cage and found that five of the nine fused levels had radiological signs of cage subsidence [11]. The subsidence was influenced by many factors, of which an important one is the higher elasticity modulus of the titanium cage. A modulus of elasticity close to cortical bone might contribute to advantages in stress distribution and load sharing, which can contribute to a lower subsidence rate and, thus, better clinical results, making PEEK cages more welcomed by surgeons.

Studies comparing titanium and PEEK cages for the treatment of cervical disc degenerative disease are rarely in the literature. Chou's team retrospectively compared the results of anterior cervical fusion using titanium cages, PEEK cages and tricortical bone grafts [12]. They noticed a better fusion rate and less subsidence in the PEEK cages group. However, the study only enrolled a small number of patients and cervical spinal function was not evaluated. In a systematic review by Kersten who compared a PEEK cage with a bone graft, titanium cage, and carbon fiber cage, no difference was found between PEEK and titanium cage [13]. Therefore, our present study was conducted to critically review and summarize the literature to compare the results of a PEEK cage with a titanium cage for the treatment of cervical degenerative disorders to identify the better choice for the surgeons.

\section{Methods}

\section{Search strategy}

Electronic searches of the Medline, Embase, Cochrane Central Register of Controlled Trials and other internet databases were performed to identify trials according to the Cochrane Collaboration guidelines. The searches included literature dating from the database origin to October 2015. We used the following search terms: "cervical", "titanium", "polyetheretherketone" or "PEEK". In addition, the Google search engine was searched manually using the same search terms to seek further relevant studies that may have been missed. Manual searches, including those of reference lists from all of the included studies, were used to identify trials that the electronic search may have failed to identify. There was no restriction on language. Two reviewers ( $\mathrm{Xu}$ and $\mathrm{Li}$ ) independently assessed the titles and abstracts of all of the reports identified by the electronic and manual searches. When inclusion was unclear based on the abstracts, the full text articles were retrieved to select those that met the eligibility criteria. We corresponded with the main authors via email to gain more data for the studies without enough details. A final confirmation of the identified studies was conducted before the meta-analysis. Any disagreements were resolved through discussion.

\section{Selection criteria and quality assessment}

Investigations that met the eligibility criteria were included in final meta-analysis; these criteria were the following characteristics: (1) the investigation compared a PEEK cage with a titanium cage for anterior cervical surgery, (2) it was a randomized or non-randomized clinical trial, and (3) the full text article provided enough data for extraction and further analysis. We excluded articles that were duplicate reports of earlier trials, post-hoc analyses of randomized controlled trial (RCT) data and articles for which we were unable to obtain the full text. Articles involving anterior plate fixation or factors to promote osteogenesis, such as BMP, were excluded. To assess the methodological quality of the randomized trials, the review authors ( $\mathrm{Xu}$ and $\mathrm{Li}$ ) used a modified version of the generic evaluation tool used by the Cochrane Bone, Joint and Muscle Trauma Group [14]. The methodological index for non-randomized studies (MINORS) form was used for non-randomized clinical trials [15]. The methodological quality of each trial was scored and ranged from 0 to 24 .

\section{Data extraction}

Two authors (Xu and $\mathrm{Li})$ independently extracted data from the included articles. Information regarding the study design, patient demographics, inclusion and exclusion criteria, interventions, outcomes, follow-up duration, and the rate of loss for each treatment group were extracted. We attempted to contact the main authors for Additional file 1 when the reported data were inadequate. Disagreements were resolved by consensus or consultation with the senior reviewer. 


\section{Data synthesis and analysis}

The meta-analysis was undertaken using RevMan 5.1 for Windows (Cochrane Collaboration, Oxford, United Kingdom). Statistical heterogeneity was assessed using a standard chi-square test (statistical heterogeneity was considered significant at $p<0.05)$ and the $I^{2}$ statistic $\left(I^{2}\right.$ value of $50 \%$ or higher was considered to indicate substantial heterogeneity) [16]. $\mathrm{I}^{2}>50 \%$ and $P<0.1$ were considered to indicate significant heterogeneity. A random-effects model was applied for data analysis when significant heterogeneity was found. A fixed-effects model was used when no significant heterogeneity was found. [17]. Odds ratios (OR) and $95 \%$ confidence intervals $(\mathrm{CI})$ were calculated for dichotomous outcomes, while mean difference (MD) and $95 \%$ CI were calculated for continuous outcomes.

\section{Results}

\section{Study characteristics}

Figure 1 shows the search strategy of the study selection and inclusion process for the study. Among the search results, 179 studies did not compare titanium and PEEK cages, one study did not provide detailed data, one study used transpedicular instrumentation, and another study used cages for pyogenic spondylodiscitis. There were 2 randomized clinical trials $[18,19]$ and 2 nonrandomized clinical trials $[12,20]$ that satisfied the predefined inclusion criteria and were included in this study. Individual patient data were available from these articles without the data for those lost to follow-up.

Characteristics of the included studies are summarized in Table 1. These studies involved 184 segments from 107 patients in the PEEK cage group and 211 segments from 128 patients in the titanium cage group. Most baseline parameters were comparable except that the patients of the PEEK cage group were older than the titanium cage group in the study by Cabraja et al. [20]. The patients in the two groups were not contemporary, with a 3 year difference in the study by Chou et al. [12]. The study by Chen et al. [18] aimed to compare outcomes of titanium and PEEK cages for the treatment of three levels of cervical spondylotic myelopathy with a 7year follow-up. The sample size was not calculated prospectively in all studies. There were 11 patients in the titanium group and 9 in the PEEK cage group that were lost at the final follow-up in the study by Chen et al.

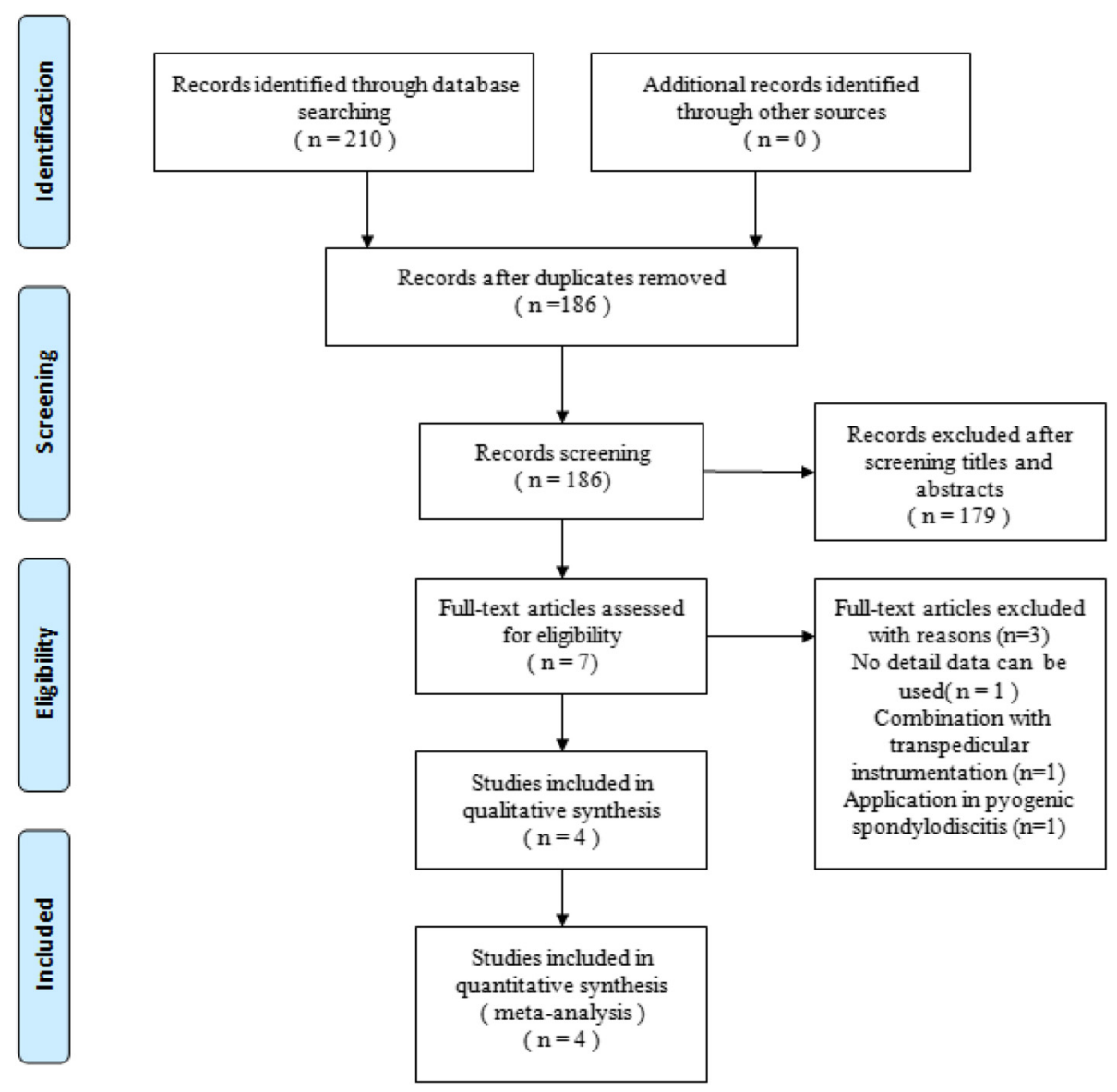

Fig. 1 PRISMA flowchart of studies 
Table 1 Characteristics of included studies

\begin{tabular}{|c|c|c|c|c|c|c|c|}
\hline study & group & Gender (M/F) & Age $(Y)$ & Segments (one/two/three) & Diseases(T/P) & Cage information & Follow-up(m) \\
\hline \multirow[t]{2}{*}{ Chou YC et al. 2008 [12] } & $\pi \mathrm{TN}$ & $11 / 16$ & 55.2 & $43(14 / 10 / 3)$ & \multirow{2}{*}{$\begin{array}{l}\text { Trauma(1/2) } \\
\text { spondylosis(10/0) } \\
\text { OPLL(1/0) HIVD(15/7) }\end{array}$} & $\begin{array}{l}\text { Non-threaded cage containing a biphasic calcium } \\
\text { phosphate ceramic }\end{array}$ & 12 \\
\hline & PEEK & $6 / 3$ & 54.2 & $15(3 / 6 / 0)$ & & containing a biphasic calcium phosphate ceramic & 12 \\
\hline \multirow[t]{2}{*}{ Niu CC et al. 2010 [19] } & TTN & $15 / 13$ & $49.5 \pm 11.3$ & $37(19 / 9 / 0)$ & \multirow[t]{2}{*}{$\begin{array}{l}\text { Radiculopathy(21/9) } \\
\text { Myelopathy(3/3) } \\
\text { Radiculomyelopathy(4/3) }\end{array}$} & $\begin{array}{l}\text { hydroxyapatite-coated, box-shaped device with } \\
\text { a tooth-threaded surface filled with a local bone } \\
\text { graft and a calcium phosphate bone substitute }\end{array}$ & $31.9 \pm 3.4$ \\
\hline & PEEK & $12 / 13$ & $52.2 \pm 10.5$ & $34(16 / 9 / 0)$ & & filled with allo-cancellous bone graft & $30.4 \pm 3.3$ \\
\hline \multirow[t]{2}{*}{ Cabraja M et al. 2012 [20] } & TTN & $26 / 18$ & $51.1 \pm 8.9$ & $44(1 / 0 / 0)$ & \multirow{2}{*}{$\begin{array}{l}\text { Radiculopathy(36/34) } \\
\text { Myelopathy(8/8) }\end{array}$} & with Plasmapore coating & $30.6 \pm 14.3$ \\
\hline & PEEK & $28 / 14$ & $57.6 \pm 11.1$ & $42(1 / 0 / 0)$ & & N & $26.1 \pm 10.0$ \\
\hline \multirow[t]{2}{*}{ Chen Y et al. 2013 [22] } & $\pi \mathrm{TN}$ & $17 / 12$ & $45.7 \pm 7.2$ & $87(0 / 0 / 3)$ & \multirow{2}{*}{$\begin{array}{l}\text { Radiculopathy }(16 / 18) \\
\text { Myelopathy }(1 / 1) \\
\text { Radiculomyelopathy }(12 / 12)\end{array}$} & $\mathrm{N}$ & 97.2 \\
\hline & PEEK & $16 / 15$ & $47.2 \pm 6.8$ & $93(0 / 0 / 3)$ & & $\mathrm{N}$ & 102.1 \\
\hline
\end{tabular}

Notes: TTN, Titanium, PEEK polyetheretherketone, OPLL ossification of the posterior longitudinal ligament, HIVD herniated intervertebral disc, $N$ non-mentioned 
However, the two groups were comparable in baseline parameters such as age, gender, operated segments and follow-up time.

\section{Risk of bias assessment}

There are some weaknesses in the methodological design of the included studies that we must keep in mind. Details about the methodological quality of the included studies are listed in Table 2. Their quality score ranged from 16 to 18. The unclear blindness was a major problem for the included studies. The outcome of assessors' blindness was only described in the study by Niu et al. The participants' and treatment providers' blindness was not clear in the studies by Niu et al. and Chen et al. There was no prospective calculation of the sample size and no data collection in the two non-randomized trials.

\section{Meta-analysis results}

\section{Clinical functional status}

Three studies evaluated clinical function using the Odom criteria [18-20]. There were no significant differences between the two groups $(\mathrm{OR}=0.89 ; 95 \% \mathrm{CI}: 0.49$ to $1.63 ; P=0.71 ; I^{2}=44 \%$; Fig. 2). There was similar postoperative cervical function in the studies by Niu et al. [19] (75 \% vs. $80 \%$, respectively; $P=0.664)$ and Cabraja et al. [20] (75 \% vs. $64.3 \%$, respectively; $P=0.395)$. Chen et al. reported better results from the PEEK cage group than the results from the titanium cage group (16/29 vs. $23 / 31$, respectively). Clinical performance measured by the neck disability index (NDI) was reported by Cabraja et al. and Chen et al. [18], but a comparison was not performed because of the significant difference in follow-up duration. Cabraja et al. showed that the final NDI was $16.89 \pm 10.24$ in the titanium cage group, while it was $17.05 \pm 9.6$ in the PEEK cage group without a significant difference $(P=0.940)$. The final NDI was $21.6 \pm 2.6$ and $15.2 \pm 2.3$ in the titanium and PEEK cage groups, respectively; this was a significant difference $(P<0.05)$ in the study by Chen et al. The final JOA score was also reported by Chen et al. and indicated that the PEEK cage group was better $(14.2 \pm 1.8)$ than the titanium cage group $(12.8 \pm 1.8)$.

\section{Radiological performance}

The fusion rate was reported in all of the studies. Chen et al. reported that all patients achieved fusion at the final 7-year follow-up, but it was not included in this meta-analysis because of the long-term follow-up. In the other three studies, 31 of the 124 segments in the titanium cage group did not show fusion at 12 months, while 5 of the 91 segments in the PEEK cage group did not show fusion at 12 months. The pooled data were analyzed using a random-effect model because heterogeneity existed $\left(I^{2}=78 \%\right)$. There was no significant difference between the two groups $(\mathrm{OR}=0.2 ; 95 \% \mathrm{CI}$ : 0.01 to $3.93 ; P=0.29$; Fig. 3 ). For the titanium cage group, a significantly lower fusion rate of $46.51 \%$ was noticed at 12 months in the study by Chou et al. [12] The fusion rate was lower in the PEEK cage group compared with the titanium cage group ( $88.1 \%$ vs. $93.2 \%$, respectively) in the study by Cabraja but the comparison was not significantly different.

Subsidence was reported in all of the studies among 33 of the 211 patients in the titanium cage group and among 11 of the 184 in the PEEK cage group. There was a significant difference between the two groups $(\mathrm{OR}=$

Table 2 Details about methodological quality of included studies

\begin{tabular}{|c|c|c|c|c|c|}
\hline Quality assessment for randomized trials & $\begin{array}{l}\mathrm{Niu} \\
\mathrm{CC}\end{array}$ & $\begin{array}{l}\text { Chen } \\
\text { Y }\end{array}$ & $\begin{array}{l}\text { Chou } \\
\text { YC }\end{array}$ & $\begin{array}{l}\text { Cabraja } \\
\text { M }\end{array}$ & $\begin{array}{l}\text { Quality assessment for non-randomized } \\
\text { trials }\end{array}$ \\
\hline Was the assigned treatment adequately concealed prior to allocation? & 2 & 1 & 2 & 2 & A clearly stated aim \\
\hline $\begin{array}{l}\text { Were the outcomes of participants who withdrew described and } \\
\text { included in the analysis? }\end{array}$ & 0 & 2 & 1 & 1 & Inclusion of consecutive patients \\
\hline Were the outcome assessors blinded to treatment status? & 2 & 0 & 0 & 0 & Prospective data collection \\
\hline Were the treatment and control group comparable at entry? & 2 & 2 & 1 & 2 & $\begin{array}{l}\text { Endpoints appropriate to the aim of the } \\
\text { study }\end{array}$ \\
\hline Were the participants blind to assignment status after allocation? & 0 & 0 & 1 & 2 & $\begin{array}{l}\text { Unbiased assessment of the study } \\
\text { endpoint }\end{array}$ \\
\hline Were the treatment providers blind to assignment status? & 0 & 0 & 2 & 2 & $\begin{array}{l}\text { A follow-up period appropriate to the aims } \\
\text { of the study }\end{array}$ \\
\hline Were care programmes, other than the trial options, identical? & 2 & 2 & 2 & 2 & Less than $5 \%$ loss to follow-up \\
\hline Were the inclusion and exclusion criteria clearly defined? & 2 & 2 & 0 & 0 & Prospective calculation of the sample size \\
\hline Were the interventions clearly defined? & 2 & 2 & 2 & 2 & Prospective calculation of the sample size \\
\hline Were the outcome measures used clearly defined? & 2 & 2 & 1 & 2 & An adequate control group \\
\hline Were diagnostic tests used in outcome assessment clinically useful? & 2 & 2 & 2 & 1 & Baseline equivalence of groups \\
\hline Was the surveillance active, and of clinically appropriate duration? & 2 & 2 & 2 & 2 & Adequate statistical analyses \\
\hline
\end{tabular}




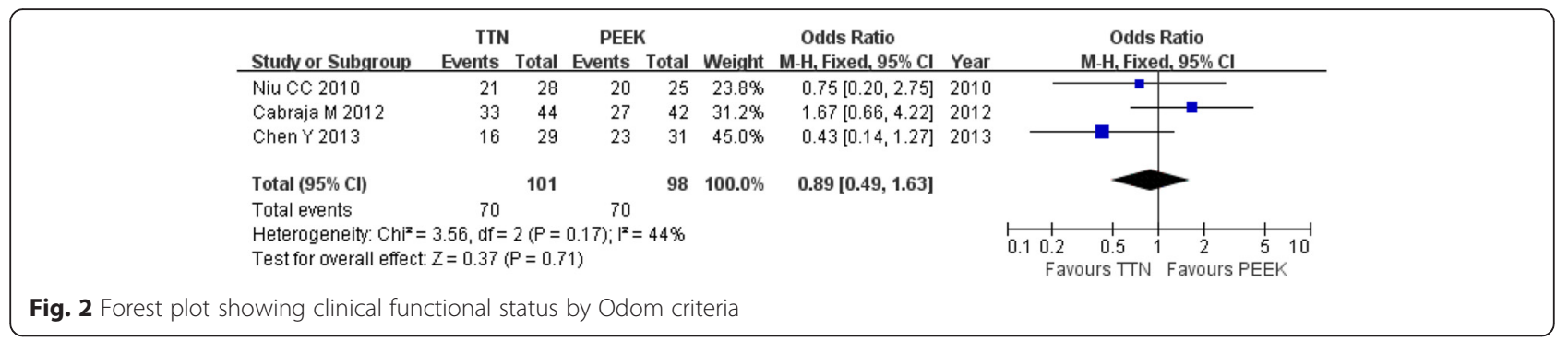

3.14; $95 \%$ CI: 1.56 to $6.30 ; P=0.001$; Fig. 4). When we excluded the data from Chen's study because of their long-term follow-up, there were many more cases of subsidence in the titanium cage group ( $\mathrm{OR}=2.4 ; 95 \%$ CI: 0.93 to $6.18 ; P=0.07$ ).

The final cervical angle and loss of correction were reported in three studies [18-20]. The methods used to measure the cervical angle were different in these articles. For the segmental angle at the surgery level, there was no significant difference between the two groups with high heterogeneity $(\mathrm{MD}=-2.28 ; 95 \% \mathrm{CI}:-4.69$ to $0.13 ; P=0.06 ; I^{2}=71 \%$; Fig. 5). Excluding the results from Chen et al., heterogeneity decreased to 0 but did not show significant difference $(\mathrm{MD}=-1.19 ; 95 \% \mathrm{CI}$ : -2.60 to $0.23 ; P=0.10)$. The loss of segmental correction was similar between the two groups ( $\mathrm{MD}=2.03 ; 95 \% \mathrm{CI}$ : -1.10 to 5.17; $\left.P=0.20 ; I^{2}=94 \%\right)$. The cervical angle was measured by using the Cobb angle from $\mathrm{C} 2-\mathrm{C} 7$ in two studies. In the study by Cabraja, there was no significant difference between the titanium and PEEK cage groups $(13.1 \pm 12.7$ vs. $13.3 \pm 7.1$, respectively; $P=0.288$ ). No data about the loss of Cobb angle from $\mathrm{C} 2-\mathrm{C} 7$ was reported in that article. In contrast, the PEEK cage group showed better a Cobb angle from $\mathrm{C} 2-\mathrm{C} 7$ than the titanium cage group $(13.65 \pm 8.92$ vs. $7.86 \pm 8.52$, respectively; $P<0.05)$ in the study by Chen et al. The loss of this angle was greater in the titanium cage group than that of the PEEK cage group $(8.59 \pm 4.67$ vs. $4.84 \pm 2.39$, respectively; $P<0.05)$.

\section{Other complications}

In addition to subsidence and loss of correction, other complications were also reported. There was 1 instance of limb numbness, 1 instance of neuropathic problem, 1 instance of weakness, and 1 instance of subluxation appeared in the titanium cage group, while there was 1 instance of wound pain in the PEEK cage group in the study by Chou. There were also 2 cases of dislocation reported in the titanium cage group by Chen.

\section{Discussion}

Titanium and PEEK cages are commonly used cages for the anterior cervical discectomy and fusion. Our present meta-analysis was conducted to compare the outcomes of both types of cages after ACDF. The results showed a similar fusion rate, loss of correction at the surgery segment, and clinical function by the Odom criteria between the titanium and PEEK cages. Although the incidence of subsidence was higher in the titanium cage group as calculated from the data for all of the studies, it changed after excluding the data from Chen's study. It seems that the titanium and PEEK cages perform similarly when used for ACDF. However, there are more considerations that should be taken when we are interpreting these results.

No matter whether a type of cage or iliac crest bone is adopted, the important aim was to realize that solid fusion is the basic foundation to maintain good clinical function. A tricortical iliac crest bone graft had been considered as the golden standard for good fusion [21]. A titanium cage can also maintain fusion well because it was first used for this practice. According to the literature, the fusion rate of the titanium cage was $84 \%$ by Yang et al. [22], 95 by Moreland et al. [23], and even $98 \%$ by Schmieder et al. [24]. It is hard to believe that the fusion rate was only $46.51 \%$ at 12 months in the included study by Chou et al. There was no clear explanation for this in Chou's study. PEEK is a biocompatible material with many perfect qualities for this application,

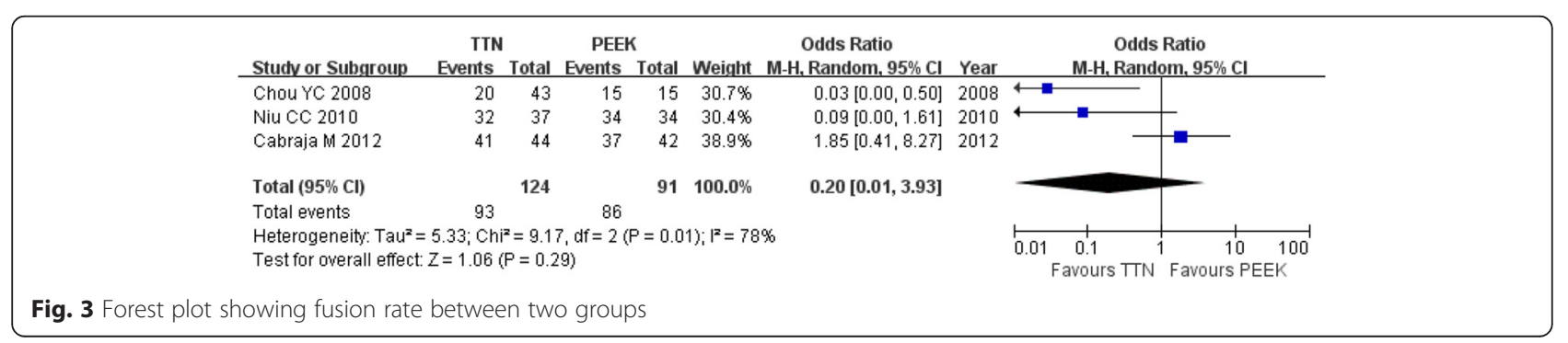




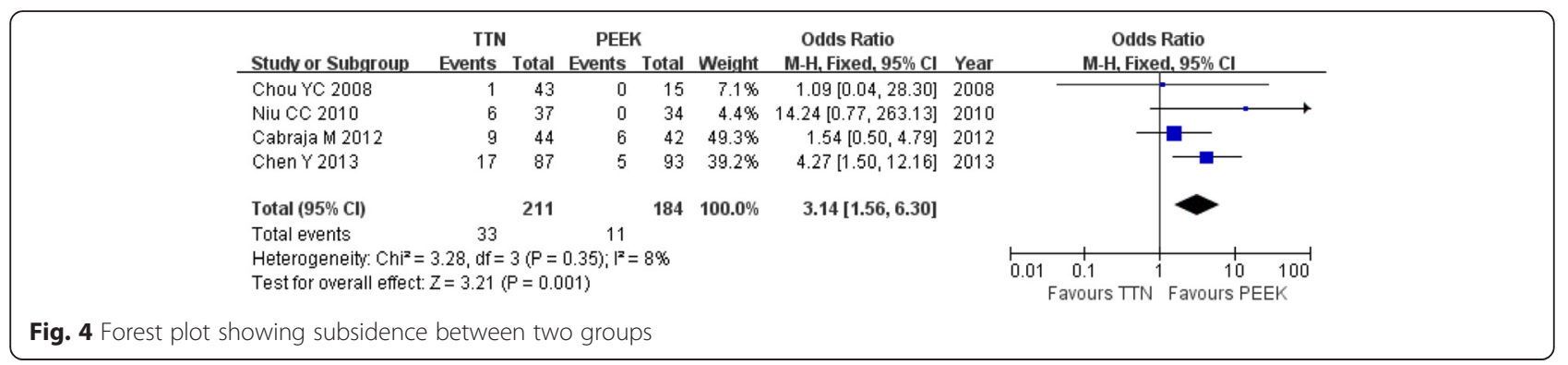

such as a corrosion resistant ability [25], the absence of cytotoxicity and mutagenicity [26] and a close elasticity modulus to bone. Based on these material characteristics, the PEEK cage have been used in ACDF with better fusion rate as reported 94 by Hwang et al. [27] and $100 \%$ by both Cho et al. [28] and Niu et al. [19]. Most of these studies had a relatively short follow-up. In the longest 7-year observation by Chen et al., all of the patients in both groups achieved bony fusion [18]. Therefore, we hypothesized that the cage material only has an effect on the fusion rate for a short time after ACDF.

Based on the Odom criteria, similar postoperative cervical function was observed in the included studies by Niu and Cabraja. However, Chen reported better results in the PEEK cage group than that of the titanium cage group after their long follow-up observation. The patients enrolled into these three studies were different. The patients received a single level ACDF in the study by Cabraja. Most of patients in the study by Niu received a single level ACDF and some of patients received a two level ACDF. It was significantly different that a three level ACDF was offered to all of the patients in the study by Chen et al. Limited by the few studies that compared titanium and PEEK cages, however, we cannot draw a conclusion that PEEK cages performed better in multiple level ACDF over a long time.

Subsidence was a common follow-up observation that can lead to deterioration of the long-term function. The incidence of cage subsidence for the titanium cages ranged from 13 to $62.5 \%$ for cases in the literature $[11,12,18-20,24,29]$. Benefitted by the better material property, the PEEK cage shows less subsidence, varying from 0 to $18 \%$ [18-20,30-32], which is consistent with our result that less cage subsidence was observed in the
PEEK cage group. However, some authors assumed that the cage subsidence was not affected by the differences in the modulus of material elasticity [12, 19]. In addition to the cage material, many risk factors, including suboptimal surgical techniques and parameters of the cage [33], may result in increased stress of the endplates and, thus, increased risk of subsidence if the bone mineral density of the vertebral body is not strong enough to bear it [34,35]. The patients of the PEEK cage group were older than those of the titanium cage group in the included study by Cabraja [20]. Patients in the PEEK cage group may suffer more from osteoporosis with a higher risk of cage subsidence.

Subsidence will a cause loss of correction of the segmental angle and the Cobb angle from C2-C7. Loss of cervical lordosis is a risk factor that contributes to degeneration in the adjacent segments [36, 37]. Kyphotic malalignment changes the dynamic kinematics of the cervical spine and accelerates the degenerative process [38]. It is the opinion of others that subsidence less than $2 \mathrm{~mm}$ into the vertebral bodies until fusion is acceptable [39]. Barsa et al. found that subsidence occurred during early follow-up and no evidence of progression appeared beyond 3 months [29]. There were no radiographic signs of progressive degenerative changes in any of the adjacent segments during the 2-year follow-up. Wu and his colleagues reported that cage subsidence did not exert a significant impact upon the long-term clinical outcomes [40]. The study by Chen et al. did not provide evidence of radiological and clinical progression after the longterm follow-up [18]. Therefore, the actual effect of loss of correction on long-term function is still unclear.

Some limitations must be clarified about our present work. The results provided in this article came from two

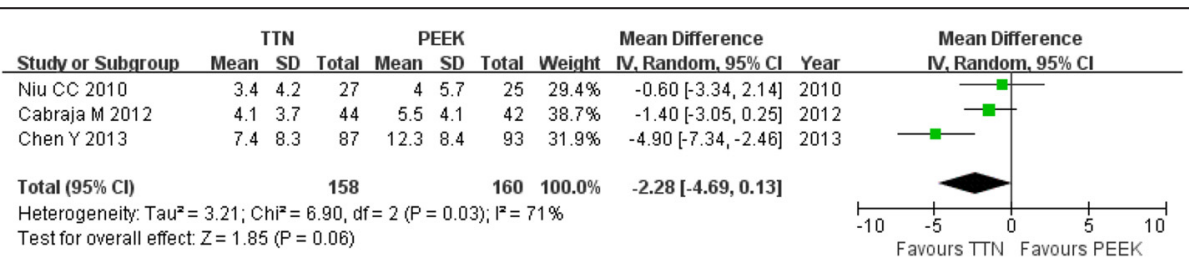

Fig. 5 Forest plot showing the final segmental angle between two groups 
RCTs and two non-RCTs, and they were analyzed together. The power of our meta-analysis is limited by the small number of high-quality RCTs. The four included studies were different in cages, levels of ACDF, and follow-up time. Although we tried our best to summarize and analyze the data, high heterogeneity existed without a subgroup analysis. Therefore, more high-quality RCTs are needed to improve the methodology, to minimize bias and to confirm the effect of these two types of cages on long-term radiographic performance and clinical function.

\section{Conclusion}

The results of this review show that titanium and PEEK cages perform similarly in attaining bony fusion and maintaining the clinical function in the anterior cervical decompression and fusion. Although more subsidence occurred in the titanium cage group, the effects of loss of local segmental angle or the whole cervical Cobb angle on cervical function in the long-term are still not clear. More high-quality, randomized controlled trials are required to further understand the application of cages in ACDF.

\section{Additional file}

Additional file 1: Raw data of RevMan 5.1 for Windows. (XLS 27 kb)

\section{Acknowledgement}

We would like to acknowledge all authors of the original studies included in this meta-analysis

\section{Funding}

This work was supported by funding from National Natural Science Foundation of China (no. 81501887) and Project of Natural Science Foundation of Tianjin (14JCQNJC11700).

\section{Availability of data and materials}

The datasets supporting the conclusions of this article are included within the article. All data and materials are contained within the manuscript.

\section{Authors' contributions}

GJX, ZJL and YW conceived of the design of the study. ZJL, PT performed and collected the data and contributed to the design of the study. YW and GJX prepared and revised the manuscript. All authors read and approved the final content of the manuscript.

\section{Competing interests}

The authors declare that they have no competing interests. The authors alone are responsible for the content and the writing of the paper.

\section{Consent for publication}

Not applicable.

\section{Ethics approval and consent to participate}

Not applicable as this is a meta-analysis of previously published papers.

\section{Author details}

${ }^{1}$ Department of Orthopedics, Tianjin Medical University General Hospital, No.154, Anshan Road, Tianjin 300052, People's Republic of China. ${ }^{2}$ Department of oncological surgery, Tianjin Nankai Hospital, Tianjin Integrated Traditional Chinese and Western Medicine Hospital, No.6
Changjiang Road, Tianjin 300100, People's Republic of China. ${ }^{3}$ Department of Orthopedics, Tianjin Hospital, No. 406, Jiefang Nan Road, Tianjin 300211. People's Republic of China.

Received: 25 November 2015 Accepted: 24 August 2016

Published online: 01 September 2016

\section{References}

1. CLOWARD RB. The anterior approach for removal of ruptured cervical disks. J Neurosurg. 1958;15(6):602-17.

2. Baba H, Furusawa N, Tanaka Y, Wada M, Imura S, Tomita K. Anterior decompression and fusion for cervical myeloradiculopathy secondary to ossification of the posterior ligament. Int Orthop. 1994;18(4):204-09.

3. Baba H, Furusawa N, Imura S, Kawahara N, Tsuchiya H, Tomita K. Late radiographic findings after anterior cervical fusion for spondylotic myeloradiculopathy. Spine (Phila Pa 1976). 1993;18(15):2167-73.

4. Younger EM, Chapman MW. Morbidity at bone graft donor sites. J Orthop Trauma. 1989:3(3):192-95.

5. Bagby GW. Arthrodesis by the distraction-compression method using a stainless steel implant. Orthopedics. 1988:11(6):931-34.

6. Brantigan JW, Steffee AD. A carbon fiber implant to aid interbody lumbar fusion. Two-year clinical results in the first 26 patients. Spine (Phila Pa 1976). 1993;18(14):2106-07

7. Ray CD. Threaded titanium cages for lumbar interbody fusions. Spine (Phila Pa 1976). 1997;22(6):667-79. 679-80.

8. Hacker RJ, Cauthen JC, Gilbert TJ, Griffith SL. A prospective randomized multicenter clinical evaluation of an anterior cervical fusion cage. Spine (Phila Pa 1976). 2000;25(20):2646-54, 2655.

9. Profeta G, de Falco R, lanniciello G, Profeta L, Cigliano A, Raja Al. Preliminary experience with anterior cervical microdiscectomy and interbody titanium cage fusion (Novus CT-Ti) in patients with cervical disc disease. Surg Neurol. 2000;53(5):417-26.

10. Hwang SL, Lin CL, Lieu AS, Lee KS, Kuo TH, Hwang YF, et al. Three-level and four-level anterior cervical discectomies and titanium cage-augmented fusion with and without plate fixation. J Neurosurg Spine. 2004:1(2):160-67.

11. Gercek E, Arlet V, Delisle J, Marchesi D. Subsidence of stand-alone cervical cages in anterior interbody fusion: warning. Eur Spine J. 2003;12(5):513-16.

12. Chou YC, Chen DC, Hsieh WA, Chen WF, Yen PS, Harnod T, et al. Efficacy of anterior cervical fusion: comparison of titanium cages, polyetheretherketone (PEEK) cages and autogenous bone grafts. J Clin Neurosci. 2008;15(11): $1240-45$.

13. Kersten RF, van Gaalen SM, de Gast A, Oner FC. Polyetheretherketone (PEEK) cages in cervical applications: a systematic review. Spine J. 2015;15(6):1446-60.

14. Sukeik M, Alshryda S, Haddad FS, Mason JM. Systematic review and meta-analysis of the use of tranexamic acid in total hip replacement. J Bone Joint Surg (Br). 2011;93(1):39-46.

15. Slim K, Nini E, Forestier D, Kwiatkowski F, Panis Y, Chipponi J. Methodological index for non-randomized studies (minors): development and validation of a new instrument. Anz J Surg. 2003;73(9):712-16.

16. Higgins JP, Thompson SG, Deeks JJ, Altman DG. Measuring inconsistency in meta-analyses. BMJ. 2003:327(7414):557-60.

17. Lau J, loannidis JP, Schmid CH. Quantitative synthesis in systematic reviews. Ann Intern Med. 1997;127(9):820-26.

18. Chen $Y$, Wang $X$, Lu X, Yang L, Yang H, Yuan W, et al. Comparison of titanium and polyetheretherketone (PEEK) cages in the surgical treatment of multilevel cervical spondylotic myelopathy: a prospective, randomized, control study with over 7-year follow-up. Eur Spine J. 2013;22(7):1539-46.

19. Niu CC, Liao JC, Chen WJ, Chen LH. Outcomes of interbody fusion cages used in 1 and 2-levels anterior cervical discectomy and fusion: titanium cages versus polyetheretherketone (PEEK) cages. J Spinal Disord Tech. 2010; 23(5):310-16.

20. Cabraja M, Oezdemir S, Koeppen D, Kroppenstedt S. Anterior cervical discectomy and fusion: comparison of titanium and polyetheretherketone cages. BMC Musculoskelet Disord. 2012;13:172.

21. Malloy KM, Hilibrand AS. Autograft versus allograft in degenerative cervical disease. Clin Orthop Relat Res. 2002;394:27-38

22. Yang X, Chen Q, Liu L, Song Y, Kong Q, Zeng J, et al. Comparison of anterior cervical fusion by titanium mesh cage versus nano-hydroxyapatite/ polyamide cage following single-level corpectomy. Int Orthop. 2013; 37(12):2421-27 
23. Moreland DB, Asch HL, Clabeaux DE, Castiglia GJ, Czajka GA, Lewis PJ, et al. Anterior cervical discectomy and fusion with implantable titanium cage: initial impressions, patient outcomes and comparison to fusion with allograft. Spine J. 2004;4(2):184-91. 191.

24. Schmieder K, Wolzik-Grossmann M, Pechlivanis I, Engelhardt M, Scholz M, Harders A. Subsidence of the wing titanium cage after anterior cervical interbody fusion: 2-year follow-up study. J Neurosurg Spine. 2006;4(6):447-53.

25. Toth JM, Wang M, Estes BT, Scifert JL, Seim HR, Turner AS.

Polyetheretherketone as a biomaterial for spinal applications. Biomaterials. 2006;27(3):324-34.

26. Katzer A, Marquardt H, Westendorf J, Wening JV, von Foerster G. Polyetheretherketone-cytotoxicity and mutagenicity in vitro. Biomaterials. 2002;23(8):1749-59.

27. Hwang SL, Hwang YF, Lieu AS, Lin CL, Kuo TH, Su YF, et al. Outcome analyses of interbody titanium cage fusion used in the anterior discectomy for cervical degenerative disc disease. J Spinal Disord Tech. 2005;18(4):326-31.

28. Cho DY, Liau WR, Lee WY, Liu JT, Chiu CL, Sheu PC. Preliminary experience using a polyetheretherketone (PEEK) cage in the treatment of cervical disc disease. Neurosurgery. 2002;51(6):1343-49. 1349-50.

29. Barsa P, Suchomel P. Factors affecting sagittal malalignment due to cage subsidence in standalone cage assisted anterior cervical fusion. Eur Spine J. 2007:16(9):1395-400.

30. Meier U, Kemmesies D. Experiences with six different intervertebral disc spacers for spondylodesis of the cervical spine. Orthopade. 2004;33(11): 1290-99.

31. Lemcke J, Al-Zain F, Meier U, Suess O. Polyetheretherketone (PEEK) Spacers for Anterior Cervical Fusion: A Retrospective Comparative Effectiveness Clinical Trial. Open Orthop J. 2011;5:348-53.

32. Pechlivanis I, Thuring T, Brenke C, Seiz M, Thome C, Barth M, et al. Non-fusion rates in anterior cervical discectomy and implantation of empty polyetheretherketone cages. Spine (Phila Pa 1976). 2011;36(1):15-20.

33. Wilke HJ, Kettler A, Goetz C, Claes L. Subsidence resulting from simulated postoperative neck movements: an in vitro investigation with a new cervical fusion cage. Spine (Phila Pa 1976). 2000;25(21):2762-70.

34. Francke El, Demetropoulos CK, Agabegi SS, Truumees E, Herkowitz HN Distractive force relative to initial graft compression in an in vivo anterior cervical discectomy and fusion model. Spine (Phila Pa 1976). 2010;35(5):526-30.

35. Yang JJ, Yu CH, Chang BS, Yeom JS, Lee JH, Lee CK. Subsidence and nonunion after anterior cervical interbody fusion using a stand-alone polyetheretherketone (PEEK) cage. Clin Orthop Surg. 2011;3(1):16-23.

36. Garber ST, Brockmeyer DL. Management of subaxial cervical instability in very young or small-for-age children using a static single-screw anterior cervical plate: indications, results, and long-term follow-up. J Neurosurg Spine. 2016;24(6):892-6.

37. Katsuura A, Hukuda S, Saruhashi Y, Mori K. Kyphotic malalignment after anterior cervical fusion is one of the factors promoting the degenerative process in adjacent intervertebral levels. Eur Spine J. 2001;10(4):320-24.

38. Takeshima T, Omokawa S, Takaoka T, Araki M, Ueda Y, Takakura Y. Sagittal alignment of cervical flexion and extension: lateral radiographic analysis. Spine (Phila Pa 1976). 2002:27(15):E348-55.

39. Thome C, Krauss JK, Zevgaridis D. A prospective clinical comparison of rectangular titanium cages and iliac crest autografts in anterior cervical discectomy and fusion. Neurosurg Rev. 2004;27(1):34-41.

40. Wu WJ, Jiang LS, Liang Y, Dai LY. Cage subsidence does not, but cervical lordosis improvement does affect the long-term results of anterior cervical fusion with stand-alone cage for degenerative cervical disc disease: a retrospective study. Eur Spine J. 2012;21(7):1374-82.

\section{Submit your next manuscript to BioMed Central and we will help you at every step:}

- We accept pre-submission inquiries

- Our selector tool helps you to find the most relevant journal

- We provide round the clock customer support

- Convenient online submission

- Thorough peer review

- Inclusion in PubMed and all major indexing services

- Maximum visibility for your research

Submit your manuscript at www.biomedcentral.com/submit
Biomed Central 